\title{
Obezitenin Sosyo-Ekonomik Belirleyicileri: OECD Ülkeleri Analizi
}

DOI: $10.26466 /$ opus.613617

\author{
Abdüsselam Sağın* - Fatih Karasaç** \\ * Dr. Öğr. Üyesi, Kırklareli Üniversitesi, İ.İ.B.F., İktisat Bölümü, Merkez/ Kırklareli/ Türkiye \\ E-Posta: abdusselam.sagin@klu.edu.tr \\ ORCID: 0000-0002-0693-1485 \\ ** Arş. Gör. Dr., Kırklareli Üniversitesi, İ.İ.B.F., Kırklareli/ Türkiye \\ E-Posta: fatihkarasac@hotmail.com \\ ORCID: $\underline{0000-0002-2966-0155}$
}

$\ddot{O} z$

Araştırmanın amacı küresel anlamda artan bir sağlık problemi olan obezitenin sosyal ve ekonomik hayatta meydana gelen değişimlerden ne derece etkilendiğinin belirlenmesidir. Bu amaç ile 29 OECD ve partner ülkesinin 2000-2013 yıllarn için obezite, sağllk harcamalarl, işsizlik, kentleşme, sigara ve alkol kullanımı ile alınan kalori miktarlarına ait veriler alınmıştır. Alınan veriler ile bu ülkelerde obezite oranlarında meydana gelen artış üzerinde sosyo-ekonomik faktörlerin etki düzeyleri araştırılmıştır. Elde edilen bulgulara göre alınan kalori miktarında meydana gelen artış, değişen sosyolojik yapının bir sonucu olarak artan kentleşme, kentleşme ile birlikte artan işsizlik oranı ve alkol kullanımının artması araştırmamızda ele alınan ülkeler için 2000-2013 yılları arasında obezite oranını arttırmaktadır. Ayrıca sağlık harcamalarında meydana gelen artış, aynı ülkelerde aynı dönem için obezite oranını azaltıcı bir etki göstermektedir. Son olarak sigara kullanımının artması ise sağlıklı beslenmeyi olumsuz etkilediğinden dolayı bireylerin kilo kaybına neden olup obezite oranlarını düşürmektedir. Fakat obezite oranlarında görülen bu düşüşs sağllklı bir düşüş olmayıp tam aksine çok daha büyük sağllk problemlerine sebep olabilmektedir.

Anahtar Kelimeler: Obezite, Sosyo-ekonomik Yapı, Sağlık Harcamaları, OECD Ülkeleri, Panel Veri Analizi 


\title{
Socio-Economic Determinants of Obesity: Analysis of OECD Countries
}

\begin{abstract}
The aim of the study is to determine the extent to which obesity, a globally increasing health problem, is affected by changes in social and economic life. For this purpose, data on the obesity, health expenditures, unemployment, urbanization, smoking and alcohol consumption and calorie intake of 29 OECD and partner countries for the years 2000-2013 were obtained. With the data obtained, the effect levels of socio-economic factors on the increase in obesity rates in these countries were investigated. According to the findings, the increase in calorie intake, increasing urbanization as a result of changing sociological structure, increasing unemployment rate with urbanization and increasing alcohol use increase the obesity rate for the countries studied in our research between 2000-2013. In addition, the increase in health expenditures has a decreasing effect on obesity rate for the same period in the same countries. Finally, the increase in cigarette smoking causes individuals to lose weight due to their negative effects on healthy nutrition and decreases obesity rates. However, this decrease in obesity rates is not a healthy decrease, but on the contrary, it can cause much greater health problems.
\end{abstract}

Keywords: Obesity, Social And Economic Structure, Healts Ependitures, OECD Countries, Panel Data Analysis 


\section{Giriş}

Obezite hem gelişmiş hem de gelişmekte olan ekonomiler için gittikçe artan bir endişe kaynağı durumundadır. Sağlık açısından risk oluşturacak düzeyde yağ birikimi olarak tanımlanan obezite, vücut kitle endeksinin ${ }^{1} 30^{\prime}$ dan büyük olması olarak da ifade edilir. Dünya Sağlık Örgütü (WHO)'nün obezite ile ilgili yapmış olduğu araştırmalar bu sorunun giderek yayginlaşan, küresel bir salgın halini aldığını göstermektedir(WHO, 2018). Bu çalışma giderek yaygin bir sorun haline gelen ve bireylerin yaşamm konforunun olumsuz etkileyen obezitenin belirleyicisi temel faktörler ile birlikte bazı sosyoekonomik faktörlerin bu sorunu ne kadar tetiklediğini incelemeyi amaçlamaktadır. Obezitenin sadece sağlık ile ilgili bir sorun olmadığı aynı zamanda bireyin içerisinde yaşadığı sosyo-kültürel ortamın da obezite üzerinde etkili olduğu düşünülmektedir. Bu sebepten dolayı çalışmamızda obeziteyi tetikleyen sağlık alanındaki veriler literatür ile uyumlu bir şekilde kullanıldıktan sonra bu sorunun temel belirleyicilerinin yanında sosyo-ekonomik faktörlerin obezite üzerinde ne derece etkili olduğu incelenmektedir. Bu amaçla obeziteyi etkileyen kalori alımı, alkol ve sigara kullanımı, sağlık harcamaları gibi değişkenler ile birlikte kentleşme ve kentleşme ile birlikte artan işsizlik oranının obezite üzerindeki etkileri analiz edilmektedir.

\section{Obeziteyi Etkileyen Sosyo-Ekonomik Faktörler}

Son dönemlerin sağlık sorunları arasında önemli bir yer alan ve gittikçe daha da fazla insanı etkileyen obezitenin nedenlerine dair yapılan birçok çalışma söz konusudur. Bu çalışmalarda obeziteye neden olan farklı değişkenlerin var olduğu görülmektedir. Obezite temelde bir sağlık sorunu olduğundan dolayı bu konuda yapılan çalışmalar da daha çok sağlık alanındaki çalışmalardan oluşmaktadır. Fakat bunun yanında teknoloji, ekonomik büyüme, şehirleşme, alınan kalori miktarı, sağlık harcamaları vb. birçok sosyoekonomik değişken de obezite üzerinde etkili faktörler olarak gösterilmektedir (Mancini vd., 2012).

\footnotetext{
${ }^{1}$ Vücut Kitle Endeksi: Kişinin kilogram cinsinden kilosu ile metre cinsinden boyunun karesinin birbirine oranIanması ile hesaplanmaktadır. Bu değerin 30 üzerinde olması kişinin sağlık açısından kişinin obez olduğunu göstermektedir.
} 
Popkin (1999), genel olarak kentleşme ile yaşam tarzının değişimi ve bu değişimin etkilerini incelediği çalışmasında artan kentleşmenin bireylerin fiziksel aktivitelerini düşürdüğünü ve gıdaya ulaşımını kolaylaştırdığını ifade etmektedir. Kırsal alanlarda yaşayan bireylerin daha fazla fiziksel aktivite sergilediğini fakat bu durumun kentleşme ile azaldığını ifade eden Popkin, sonuç olarak kentleşmenin değişen yaşam tarzı ile birlikte obeziteyi tetikleyen bir unsur olduğunu ifade etmektedir. Philipson ve Posner (1999), Philipson (2001) ve Lakdawalla ve Philipson (2002) obezite ile ilgili yapmış oldukları çalışmalarda ortak sonuç olarak teknolojik ilerleme ile birlikte bireylerin çalışma hayatlarında daha az fiziksel aktivite sergilediklerini ve bu durumun da obeziteyi arttırdığını iddia etmektedir. Maillard vd. (1999) ise Avrupa ülkeleri için obezite oranlarının değişimini analiz ettiği çalışmasında 1980-1991 yılları arasında tüm meslek gruplarında hem kadınlar hem de erkekler için obezitenin arttığı sonucuna ulaşmışlardır. Nestle ve Jacobson (2000) ise kalori alımı ve fiziksel aktivite yoğunluğu ile obezite arasındaki ilişkiyi incelemiş, alınan kalori miktarındaki artış ve fiziksel aktivitelerdeki azalışın obeziteyi arttırdığı sonucuna ulaşmışlardır. Laitinen vd. (2002) işsizlik ile obezite arasındaki ilişkiyi inceledikleri çalışmalarında ise işsizlikten doğan ruhsal bozuklukların etkisi ile obezitenin artacağı sonucuna ulaşmaktadırlar. Lakdawalla ve Philipson (2002) ise ABD ekonomisi için gerçekleştirdikleri analizde artan eğitim düzeyinin obeziteyi azalttı̆̆ sonucuna ulaşmışlardır. Bu sonuç Wardle vd. (2002) çalışmasında elde edilen bulgular ile de benzerlik göstermektedir. Laureiro ve Nayga (2004)

OECD ülkeleri için obezite oranını etkileyen faktörleri inceledikleri çalışmalarında artan kentleşmenin, alınan kalori miktarındaki artışı ve kadınların işgücü piyasasına daha fazla katılmalarının obeziteyi arttıran unsurlar olduğu sonucuna ulaşmışlardır. Komlos ve Baur (2004) ve Maheshwari vd. (2005) ise çalışmalarında ABD'de erkekler arasında 1970'lerde obezitenin düşük gelir grupları için bir sağlık problemi olduğunu fakat değişen sosyo-ekonomik yapı ile birlikte obezitenin son otuz yılda artık orta ve yüksek gelir düzeyinde yer alan bireyler için bir sağlık problemi haline geldiği sonucuna ulaşmışlardır. Huffman ve Rizov (2007) ise Rusya için obezitenin belirleyici unsurlarını analiz ettikleri çalışmalarında, çarpıcı bir sonuç olarak Rusya ekonomisinin planlı ekonomiden serbest piyasa ekonomisine geçişi ile birlikte obezite oranlarının yaklaşık \%38 arttığı sonucuna ulaşmışlardır. 1994-2004 yılları arasında Rusya'da uygulanan izleme anketi 
verilerini kullandıkları çalışmalarında kalori alımının obeziteyi ciddi anlamda arttırdığını gözlemlemişlerdir. Bununla birlikte cinsiyet, eğitim ve gelir düzeyinin de yine obezitenin belirleyici unsurları arasında yer aldığını gözlemlemişlerdir. Huffman ve Rizov 'un bu çalışmada elde ettikleri bulgular aynı zamanda Chou vd. (2004), Rashad vd. (2006) çalışmalarında elde edilen bulgular ile de paralellik göstermektedir. Yine bu çalışmada elde edilen bulgular arasında yer alan artan eğitim düzeyinin obeziteyi azalttığ sonucu da Lakdawalla ve Philipson (2002)'un ABD ekonomisi için yaptıkları çalışmada elde ettikleri bulgular ile benzerlik göstermektedir. Finkelstein ve Strombotne (2010) ise obezite ile ilgili yapmış oldukları çalışmalarında bireylerin ekonomik gücünde meydana gelen artışların yüksek enerji veren ve lezzetli ürünlere ulaşmayı kolaylaştırdığg, bireylerin evde, iş yerinde ve ev ile iş yeri arasında daha az hareket etmelerine neden olarak obeziteyi arttırdığ sonucuna ulaşmışlardır. Yine bu çalışmadan elde edilen bulgulara göre ekonomik gücün artışı bireyler için sağlık harcamalarını daha ucuz ve ulaşılabilir bir hale getirdiği için bireylerin diyet ve egzersiz yapma motivasyonlarını da düşürmektedir. Georgiou (2013) ise Batı Avrupa ülkeleri ve ABD için panel veri analizi kullanarak yaptığı çalışmasında gelir dağılımı ile obezite arasındaki ilişkiyi incelmektedir. Analiz sonuçlarına göre Gini katsayısı yükseldikçe obezite oranı da artmaktadır. Halıcıoğlu (2013) Finlandiya ekonomisi için obezitenin dinamiklerini analiz ettiği çalışmasında şehirleşme ve işsizlik oranındaki artışın obeziteyi arttırdığı, sağlık harcamalarındaki artışın ise obeziteyi azalttığı sonucuna ulaşmıştır. Sturm vd. (2013) ise yaptıkları çalışmada Güney Afrika için obezite, sigara ve alkol kullanımının sağlık harcamaları üzerindeki etkilerini incelemektedirler. Bu amaçla 2010 yılı boyunca 70 bin Güney Afrikalı ile görüşen araştırmacılar obezite ve sigara kullanımının sağlık harcamalarını önemli ölçüde arttırdığı sonucuna ulaşmışlardır. Ayrıca aşırı obezitenin sağlık harcamalarını yaklaşık iki katına çıkardığı sonucu da yine bu çalışmanın bir diğer dikkat çekici sonucu olarak karşımıza çıkmaktadır. Agrawal ve Agrawal (2017) ise Hintli kadınlar arasında obezite ile ilgili yaptıkları araştırmada sağlık harcamaları ile obezite arasındaki ilişkiyi incelemiş ve önleyici sağlık hizmetleri sunularak obezitenin engellenmesini sağlamanın obezite sonrası yapılan sağlık harcamaları miktarından daha düşük olduğu sonucuna ulaşmışlardır. Bu durum obeziteyi önleme amacı ile uygulanacak kamu politikalarının maliyet etkin olduğu sonucunu da ortaya koymaktadır. Bansal ve Zilberman (2017) ise 194 
ülkenin 2002, 2005 ve 2010 yıllarına ait veriler ile yaptıkları çalışmalarında obeziteyi önleyici sağlık harcamalarının verimliliğini analiz etmektedirler. Elde ettikleri bulgulara göre sağlık harcamalarının yaşam süreleri üzerindeki etkisinin daha yüksek olabilmesi obezitenin düşük düzeylerde tutulabilmesi ile mümkün olabilmektedir. Hayes vd. (2016) Avustralya' da çocuklar üzerine yapmış oldukları çalışmalarında erken yaştaki çocuklar için yapılan obeziteyi önleyici sağlık harcamalarının etkisi üzerinde durmaktadırlar. Elde ettikleri bulgular erken yaşta şişmanlığın önlenmesinin sağlık harcamalarını düşürdügüunü göstermektedir. Bu sonuç obezite sorunu ile mücadelenin aslında çocuk yaşlardan başlanması gerektiği gerçeğini de destekler niteliktedir.

\section{Veri Seti}

Çalışmanın bu kısmında panel veri analizi kullanılarak obezitenin dinamikleri 29 OECD ve partner ülkesi ${ }^{2}$ için ele alınmaktadır. Çalışmada bağımlı değişken olarak ülkelerdeki obez nüfusun ülke nüfusuna oranı kullanılmıştır. Obezitenin dinamiklerini oluşturan değişkenler ise literatür ile uyumlu bir şekilde kişi başına düşen sağlık harcamaları, işsizlik oranları, kentleşme (şehirleşme) oranı, kişi başına düşen alkol tüketimi, sigara tüketenlerin toplam nüfusa oranı ve kişi başına alınan günlük kalori miktarı olarak belirlenmiştir.

Obezite değişkeni, vücut kitle indeksi 30'un üzerinde olan 18 yaş üstü yetişkin bireylerin toplam nüfus içerisindeki oranını göstermektedir. Sağlık harcamaları değişkeni, toplam sağlık harcamalarının GSYH'ye oranı şeklinde kullanılmaktadır. İşsizlik oranı, ülkelerin işgücü içerisinde yer alan çalışamayan nüfusu ifade etmektedir. Şehirleşme oranı, ulusal istatistik büroları tarafından tanımlanan kentsel alanlarda yaşayan insanların toplam nüfus içerisindeki oranına işaret etmektedir. Alkol tüketimi değişkeninde ise kişi başına tüketilen alkol miktarı litre şeklinde kullanılırken; sigara kullanımı, toplam nüfus içinde sigara kullananların oranı şeklinde ele alınmaktadır. Son olarak günlük kalori miktarı değişkeni ise bir günde kişi başına tüketilen kalori miktarın tanımlamaktadır.

\footnotetext{
${ }^{2}$ Çalışmada analiz edilen ülkeler: İngiltere, Fransa, Kanada, İtalya, Japonya, Güney Kore, Meksika, Güney Afrika, Türkiye, ABD, Almanya, Finlandiya, İzlanda, Hollanda, Norveç, İsveç, İsviçre, Brezilya, Şili, Çin, Hindistan, Rusya, Kosta Rika, Kolombiya, Avustralya, Avusturya, Belçika, Çek Cumhuriyeti ve Danimarka.
} 
Analizde kullanılan verilerden, obezite ve günlük kalori miktarı değişkenleri Dünya Sağlık Örgütü veri tabanından, sağlık harcamaları ve alkol tüketimine ilişkin veriler OECD istatistiklerinden, işsizlik ve şehirleşme verileri ise Dünya Bankası verilerinden temin edilmiştir.

\section{Yöntem}

Son otuz yılda özellikle ampirik analiz içeren çalışmalarda panel veri analizi sıklıkla kullanılmaktadır. Panel veri analizinin sıklıkla kullanılmasında, tahmin yöntemlerinin ve teorik altyapının hızlı bir şekilde gelişimi etkili olmuştur (Greene, 2003). Bunun yanı sıra yatay kesit ve zaman verilerinin bir arada kullanılmasına imkân sağlayan panel veriler, daha fazla veriyle çalışmayı ve daha yüksek serbestlik derecesi ile tahminler yapmayı mümkün kılmaktadır. Bunun yanı sıra gözlem sayısında meydan gelen artış neticesinde çoklu doğrusal bağlantı sorunu da ortadan kalkmaktadır (Hsiao, 2002). Panel verilerin kullanılmasının diğer avantajları ise, panel veri metodunun yatay kesitlerde meydana gelen heterojenliği göz ardı etmemesi, model spesifikasyon hatası sebebiyle oluşacak problemlere çözüm getirebilmesi, çoklu doğrusal bağlantı sorununu azaltması ve kapsamlı davranışsal modelleri test edebilmesi şeklinde olduğu vurgulanmaktadır (Baltagi, 2005).

Panel veri regresyon modeli Denklem 1'deki eşitlik kullanılarak kurulmaktadır (Baltagi, 2011):

$$
y_{i t}=a+x_{i t}^{i}+u_{i t}
$$

Denklem 1'deki eşitlikte $i,(i=1,2, \ldots, N)$ kesitini ifade ederken $t,(t=$ $1,2, \ldots, T)$ ile zaman periyodunu tanımlamaktadır. $u_{i t}$ ise hata teriminin bütün zaman ve birimler için bağımsız olduğu ve $u_{i t} \approx I I D\left(0, \sigma^{2}\right)$ şeklinde dağılıma sahip olduğu varsayılmaktadır.

Panel veri modelleri, Havuzlanmış En Küçük Kareler, Sabit Etkiler ve Rassal Etkiler olarak ifade edilen üç farklı model şeklinde değerlendirilmektedir³. Buna göre birim ve zaman etkilerinin homojen olduğu ve hata terimi her iki etkiyi de içermediği durumda etkin ve tutarlı tahminler veren Havuzlanmış En Küçük Kareler yöntemi, eğim parametrelerinin tüm yatay kesit birimler için

${ }^{3}$ Panel veri analizi ile ilgili kapsamlı bilgi için bkz. Chamberlain (1982, 1984), Hsiao (2004) ve Baltagi (2005). 
aynı, sabit parametrenin birimler arasında farklılaştığı (birim etki içerdiği) durumda Sabit Etkiler yaklaşımı ve eğim parametreleri yatay kesitler arasında değişiyorsa ve örnekteki birimler rassal olarak seçilebiliyor ise Rassal Etkiler yaklaşımı kullanılmaktadır.

Diğer taraftan panel verilere ilişkin en uygun modelin hangisinin olduğu Hausman, Breusch-Pagan LM, F, Olabilirlik ve F testleri ile sonucunda karar verilmektedir (Mohan ve Mirmirani, 2007). Panel veri modellerinin uygun tahmin yönteminin seçilmesi için gerekli hipotezler ve hipotezlere ilişkin test sonuçları Tablo 1'de verilmiştir.

Tablo 1. Panel Veri Analizine İlişkin Test Sonuçları

\begin{tabular}{|c|c|c|c|}
\hline Hipotez & Test & Test İstatistiği & Karar \\
\hline $\begin{array}{l}\text { Ho:Havuzlanmış } \\
\text { geçerlidir. } \\
\text { Ha: Sabit etkili model geçerlidir. }\end{array}$ & F-testi & $\begin{array}{l}1499.82 \\
(0.000)\end{array}$ & $\begin{array}{l}\mathrm{H}_{0} \text { reddedilir. Sabit etkili } \\
\text { model geçerlidir. }\end{array}$ \\
\hline $\begin{array}{l}\mathrm{H} 0: \text { Havuzlanmış } \\
\text { geçerlidir. } \\
\text { Hodel }\end{array}$ & LM-testi & $\begin{array}{l}2120.38 \\
(0.000)\end{array}$ & $\begin{array}{l}\mathrm{H}_{0} \text { reddedilir. Rassal etkili } \\
\text { model geçerlidir. }\end{array}$ \\
\hline $\begin{array}{l}\text { Ho: Rassal etkili model geçerlidir. } \\
\text { Ha: Sabit etkili model geçerlidir }\end{array}$ & Hausman & $\begin{array}{l}16.683 \\
(0.011)\end{array}$ & $\begin{array}{l}\mathrm{H}_{0} \text { reddedilir. Sabit etkili } \\
\text { model geçerlidir. }\end{array}$ \\
\hline
\end{tabular}

F testi, havuzlanmış model ile sabit etkili modelin seçiminde kullanılmış olup test istatistiğine göre sıfır hipotezi reddedilip sabit etkili modelin geçerli olduğu sonucuna ulaşılmıştır. Breusch-Pagan LM testi ise havuzlanmış ile rassal etkili modelin seçiminde kullanılıp test sonucuna göre sıfır hipotezi reddedilip rassal etkili modelin geçerli olduğu belirlenmiştir. Sabit ve rassal etkili modeller arasındaki seçim ise Hausman testi ile test edilip 0.05 anlamlılık düzeyinde sıfır hipotezi reddedilip bu çalışmada test edilen ilişkilerin analizi için sabit etkili modelin geçerli olduğu sonucuna ulaşılmıştır.

Panel veri ${ }^{4}$ modellerinin tercih edilebilmesi için bazı temel varsayımları karşılaması beklenmektedir. Bu temel varsayımlar, hata teriminin birimler arasında korelasyon (yatay kesit bağımlılığı) barındırmadığı, birim içinde ve birimler arasında eşit varyanslı olduğu (homoskedasite) ve birim içinde korelasyon (otokorelasyon) barındırmadığı varsayımlarına dayanmaktadır.

\footnotetext{
${ }^{4}$ Bu çalışmada yatay kesit bağımlıı̆̆ı olarak Pesaran (2004) testi kullanılmıştır. Bu testte ele alınan durum büyük $N$ ve küçük $T(N>T)$ durumunu ele almaktadır. Analizde de yatay kesit sayısı, zaman boyutundan büyük olduğu $(N=29>T=14)$ için bu test kullanılmıştır
} 
Modelde söz konusu bu temel varsayımların hepsi birden karşılanıyorsa panel veri yaklaşımına uygun yöntemlerinden biri tercih edilebilmektedir (Hsiao, 2002; Baltagi, 2013).

Çalışmamızda panel veri analizini gerçekleştirmek için STATA paketi kullanılmıştır. Bu çerçevede çalışmamızda kullanılan model denklemi aşağıda yer almaktadır.

$$
\begin{gathered}
\log (\text { obz })_{i t}=\log (s h)_{i t}+\log (\text { unemp })_{i t}+\log (\text { urb })_{i t}+(\text { alc })_{i t}+ \\
(\text { sigara })_{i t}+\log (k c l)_{i t}+u_{i t}
\end{gathered}
$$

Burada bağımlı değişken olan log(obz), vücut kitle indeksi 30 üzerinde olan 18 yaş üstü yetişkin bireylerin toplam nüfusuna oranın göstermektedir. $\log (\mathrm{sh})$, toplam sağlık harcamalarının GSYH'ye oranı şeklinde kullanılmaktadır. $\log$ (unemp), toplam nüfus içindeki işsiz nüfus oranın göstermektedir. $\log (\mathrm{urb})$, kentsel alanlarda yaşayan insanların toplam nüfusa oranın işaret etmektedir. (alc), 15 yaşından büyük bireylerin kişi başına tüketilen alkol miktarı iken (sigara) 15 yaşından büyük sigara kullanan bireylerin toplam nüfus içindeki oranını temsil etmektedir. $\log (\mathrm{klc})$ ise bir günde kişi başına tüketilen kalori miktarı olarak tanımlanmaktadır. Son olarak, analizde kullanılan değişkenlere ilişkin tanımlayıcı istatistikler Tablo 2'de yer almaktadır.

Tablo 2. Tanımlayıcı İstatistikler

\begin{tabular}{lccccccc}
\hline & $\log (\mathbf{o b z})$ & $\log (\mathbf{s h})$ & $\log ($ unemp) & $\log ($ urb) & alkol & sigara & $\log (\mathbf{k a l o r i})$ \\
\hline Ortalama & 2.714 & 2.030 & 1.771 & 4.303 & 8.349 & 21.173 & 8.077 \\
Medyan & 2.909 & 2.082 & 1.844 & 4.365 & 8.500 & 21.650 & 8.091 \\
Maksimum & 3.535 & 2.797 & 3.302 & 4.582 & 19.800 & 35.500 & 8.250 \\
Minimum & 0.470 & 1.177 & -1.069 & 3.320 & 0.900 & 7.600 & 7.721 \\
Standart & & & & & & & \\
Hata & 0.679 & 0.311 & 0.620 & 0.232 & 3.460 & 6.172 & 0.106 \\
Gözlem & 406 & 406 & 406 & 406 & 406 & 406 & 406 \\
\hline
\end{tabular}

\section{Bulgular}

Tahmin edilen sabit etkiler modeli aşağıda Tablo 3'te yer almaktadır. Modeldeki yatay kesit bağımlılığı ve farklı varyans-otokorelasyon tanımlayıcı testleri, modelde yatay kesit bağımlılığı, artıklar da farklı varyans ve otokorelsyonlu olduğunu göstermektedir. 
Tablo 3. Panel Veri Analizi Sabit Etki Modelinin Tahmin Sonuçlart ${ }^{5}$

\begin{tabular}{lclll}
\hline & Katsay1 & Standart Hata & t istatistik & Olasılik \\
\hline $\log (\mathrm{sh})$ & 0.2196 & 0.0313 & 7.00 & $0.000^{* * *}$ \\
$\log (\mathrm{unnemp})$ & $-0,0022$ & 0.0055 & -0.40 & 0.688 \\
$\log (\mathrm{urb})$ & 1.9652 & 0.0735 & 26.72 & $0.000^{* * *}$ \\
$\log (\mathrm{kalori})$ & 0.7980 & 0.1096 & 7.28 & $0.000^{* * *}$ \\
alkol & -0.0041 & 0.0028 & -1.47 & 0.143 \\
sigara & -1.9353 & 0.1145 & -16.90 & $0.000^{* * *}$ \\
Sabit & -6.7418 & 0.8864 & -7.61 & $0.000^{* * *}$ \\
R-kare & 0.8669 & F-İstatistik & 402.62 & $0.000^{* * *}$ \\
Sigma_u & 0.5533 & & & \\
Sigma_e & 0.0431 & & & \\
\hline
\end{tabular}

NOT: ***\%1, seviyesinde istatistiksel anlamlılı̆̆ı tanımlamaktadır.

Tablo 2'te yer alan panel veri sabit etkiler modeline ilişkin yatay kesit bağımlılığı ve farklı varyans-otokorelasyon tanımlayıcı testleri yapılmıştır. Söz konusu bu testlere ilişkin sonuçlar Tablo 4'te yer almaktadır. Yatay kesit bağımlılığı tespit edilen panel verinin değişen varyans varsayımını sağlayıp sağlamadığı Değiştirilmiş Wald testi ile otokorelasyon varsayımı ise Wooldridge Testi yardımıyla kontrol edilmiştir. Değiştirilmiş Wald testi sıfır hipotezi \%5 anlamlılık düzeyinden düşük olduğu için kabul edilmiş ve modelin sabit varyans varsayımı sağladığı görülmüş̧ür. Otokorelasyon sorunu ise artık terimlerde farklı varyans olduğu sonucunu ortaya çıarmıştır. En nihayetinde yapılan testler modelde yatay kesit bağımlılığı, artıklarda farklı varyans ve modelin otokorelsyonlu olduğunu göstermektedir. Bu nedenle dirençli (robust) sabit etkiler modeli ile model tekrar tahmin edilmiştir.

Tablo 4. Modeldeki Yatay Kesit Bă̆ımlılı̆̆ı Ve Farklı Varyans-Otokorelasyon Tanımlayıcı Testleri

\begin{tabular}{lll}
\hline Yatay Kesit Bağımlılı̆̆ Testi & $6.758(0.000)$ & Yatay kesit bağımlılığı var \\
\hline Farklı Varyans (Modifiye Wald Testi) & $3492.36(0.000)$ & Artık terimlerde farklı varyans var \\
\hline Otokorelasyon (Wooldridge) & $190.589(0.000)$ & $\begin{array}{l}\text { Artık terimlerde otokorelasyon } \\
\text { var }\end{array}$ \\
\hline
\end{tabular}

Tahmin edilen sabit etkili modelde yatay kesit bağımlılığı olması ve diğer tanımlayıcı testlerin modelin geçerliliğini göstermemesinden dolayı, DricollKraay (1998) yöntemi ile tekrar tahmin edilerek dirençli katsayı tahminleri

\footnotetext{
${ }^{5}$ Modelde zaman etkisi olup olmadığı test edilip $\chi^{2}=12.63$ (0.367) değeri elde edilip zaman etkisinin olmadığı ve tek yönlü panel veri modelinin geçerli olduğu sonucuna ulaşılmıştır.
} 
Tablo 5'te verilmiştir. Bu sonuçlara göre, modelin belirlilik katsayısı $\left(\mathrm{R}^{2}\right)$ \%86.69 olup modeldeki bağımsız değişkenler, obezitenin yaklaşık \%87'sini açıklamaktadır. F-istatistiği, katsayıların topluca anlamlı olduğunu gösterip, katsayılar tek tek incelendiğinde, unemp değişkeni istatistiksel olarak anlamlı tahmin edilmemiştir. Ayrıca alkol değişkeni istatistiksel olarak anlamlı olmasına rağmen obezite üzerindeki etkisi sıfıra çok yakın olarak tahmin edilmiştir. En yüksek pozitif etki kentleşme iken en yüksek negatif etki sigara olarak dirençli tahminciler elde edilmiştir.

Model sonuçlarına göre işsizlik, alkol ve sigara değişkenlerinin obezite üzerinde negatif bir etkisi söz konusu iken kentleşme, günlük kalori alımı ve sağlık harcamaları değişkenlerinin obezite üzerindeki etkilerinin pozitif olduğu Tablo 4'ten görülmektedir. Buna göre, açıklayıcı değişkenler arasında kentleşme değişkeni obezite oran üzerinde en yüksek etkiye sahip değişken olarak görülmektedir. Zira kentleşme oranındaki \%1'lik artış obeziteyi \%1.96 oranında arttırdığı gözlenmektedir. Bu oran, obezite ile kentleşme arasında yüksek oranda bir ilişkinin olduğunu göstermektedir. Bu sonucun ortaya çıkmasında, kentsel alanlarda daha az fiziksel aktivite gerektiren istihdam alanlarının olması, kentlerde yoğun bir şekilde bulunan fast-food restoranları, rahat ve konforlu yaşamın etkili olduğu söylenebilir. Bu bulgu, Loureiro ve Nagya (2004) ve Halıcıoğlu (2013) çalışmaları ile de uyumludur. Bu durum kentleşmenin OECD ülkelerinde obezitenin artmasında önemli faktörlerden biri olduğuna işaret etmektedir. Obezite oranının günlük kalori alımı oranına göre esnekliği ise 0,79 'dur ve günlük kalori alımı oranındaki \%1'lik bir artışın obezite oranın $\% 0.79$ oranında arttırdığını göstermektedir. Bu sonuç ile paralel biçimde Rosin (2007)'de çalışmasında yüksek miktarda kalori alımının obeziteyi önemli miktarda arttırdığ1 sonucunu elde etmiştir. Obezite üzerindeki etkinin pozitif olduğu son açıklayıcı değişken toplam sağlık harcamalarının GSYH'ye oranını gösteren değişkendir. Buna göre kişi başına sağlık harcamalarındaki \%1'lik artış obezite oranını \% 0,21 oranında arttırdığ tahmin edilmiştir. Bu sonucun aksine sağlık harcamalarındaki artış obeziteyi azaltacağ 1 düşünülmektedir.

Diğer taraftan işsizlik oranı, alkol kullanımı ve sigara kullanımı ile obezite ve arasındaki ilişkinin negatif yönlü olduğu Tablo $4^{\prime}$ ten görülmektedir. İşsizliğin obezite üzerindeki etkisine bakıldığında, işsizlik oranındaki \%1'lik artış, obezite oranında \%0,002'lik bir azalışa neden olmaktadır. Buna göre örneklemde yer alan ülkelerde işsizliğin obezitenin azalmasında çok az bir 
etkisi olduğu tahmin edilmiştir. İşsizliğin yoğun olduğu ülkelerde obezitenin diğer ülkelere kıyasla daha düşük düzeylerde olduğu söylenebilir. Alkol tüketiminin obezite üzerindeki etkisi, diğer açıklayıcı değişkenlere göre nispeten küçük gözükmektedir. Çünkü alkol tüketimindeki \%1'lik bir artışın obezite oranını \%0,004 oranında azalttığını göstermektedir. Bu sonuç alkol tüketiminin yoğun olduğu ülkelerde obezite oranlarının da diğer ülkelere göre nispeten daha az seviyelerde olduğunu göstermektedir. Son olarak sigara kullanımı ile obezite ilişkisinin esnekliği 1,93’tür. Buna göre sigara kullanımında ortaya çıkan \%1 birimlik artış obeziteyi \%1.93 oranında azaltmaktadır. Bu bulgu ile paralel bir şeklide Özçiçek vd. (2007) çalışmaları gibi birçok çalışmada sigara kullananların sigara kullanmayanlara göre daha düşük kiloda oldukları vurgulanmaktadır.

Tablo 5. Panel Veri Analizi Dirençli (Robust)Sabit Etki Modelinin Tahmin Sonuçları

\begin{tabular}{lclll}
\hline & Katsayı & Standart Hata & t istatistik & Olasılık \\
\hline $\log (\mathrm{sh})$ & 0.2196 & 0.0342 & 6.41 & $0.000^{* * *}$ \\
$\log ($ isz $)$ & $-0,0022$ & 0.0036 & -0.61 & 0.555 \\
$\log ($ kent) & 1.9652 & 0.0526 & 37.35 & $0.000^{* * *}$ \\
$\log ($ kalori) & 0.7980 & 0.0717 & 11.13 & $0.000^{* * *}$ \\
alkol & -0.0041 & 0.0011 & -3.47 & $0.004^{* * *}$ \\
sigara & -1.9353 & 0.1316 & -14.70 & $0.000^{* * *}$ \\
Sabit & -6.7418 & 0.5171 & -13.04 & $0.000^{* * *}$ \\
R-kare & 0.8669 & F-İstatistik & 2787.48 & $0.000^{* * *}$ \\
\hline
\end{tabular}

NOT: ***\%1, seviyesinde istatistiksel anlamlılı̆̆ı tanımlamaktadır.

\section{Tartışma ve Sonuç}

Çalışma sonucunda elde edilen bulgulara göre bireylerin almış oldukları günlük kalori miktarlarının artması obezite oranlarını da arttırmaktadır. Yetişkin bir bireyin günlük alması gereken ortalama kalori miktarı yaklaşık 2000 kalori düzeyindedir. Bunun üzerinde bir kalori alma durumu doğal olarak kilo artışına ve obeziteye neden olacaktır. Değişen çalışma ve yaşam düzeninin bireylerin hazır gıda veya fast-food tüketimini arttırdı̆̆ı, hazır gıdaların ve fast-food türü yiyeceklerin de yüksek kalori içerdiği düşünüldüğünde dünya üzerinde obezitenin sürekli artan bir trende sahip olması kaçınılmaz bir durum olacaktır. Çalışma sonucunda elde edilen bir diğer sonuca göre artan kentleşme, obeziteyi tetikleyen bir unsur olarak karşımıza çıkmaktadır. Kırsal kesimde yaşamak durumunda olan kişilerin 
daha fazla hareket ettikleri ve doğal olarak daha fazla kalori yaktıkları göz önünde bulundurulduğunda şehirleşmenin, bireylerin gün içerisindeki hareket miktarını düşürdüğü sonucu ortaya çıkmaktadır. Kentleşme ile birlikte çalışma şartları değişmekte ve bireyler daha çok masa başı işler gibi hareket gerektirmeyen alanlarda çalışmaktadırlar. Bu durumun bir sonucu olarak daha az enerji harcamakta ve daha az kalori yakmaktadırlar. Değişen çalışma şartları en nihayetinde bireylerin vücut kitle endeksinin artmasına ve obeziteye yol açmaktadır. Artan şehirleşmenin bir diğer ekonomik etkisi ise artan işsizlik oranları olmaktadır. Değişen sosyolojik ve ekonomik yapı ile birlikte şehir hayatının daha cazip hale gelmesi bireylerin köyden kente göç etmesini kolaylaştırmakta ve doğal olarak şehirlerde işsizlik oranı artmaktadır.

Tüm sonuçlar obezitenin dünya üzerinde 21. yüzyılda yaşanan önemli sağlık sorunları arasında olduğunu göstermesi açısından oldukça önemlidir. Obez nüfusun sürekli artması ve obezite görülme yaşının sürekli düşüyor olması bu sorunun önümüzdeki yıllarda da ülkeler için önemli bir sağlık sorunu olacağını göstermektedir. Obezite ve beraberinde ortaya çıan sağlık problemlerinin önlenmesi bireyler ve ülke yönetimleri için büyük önem arz etmektedir. Bu amaçla bireylerin sağlıklı ve organik gıdalara ulaşımı kolaylaştırılmalı ve bu alanda bilinçlenmeleri sağlanmalıdır. Ayrıca artan kentleşmenin önüne geçilmeli ve bireylerin kırsal alanda da yaşam standartlarını arttırıcı teşvikler geliştirilmelidir. Son olarak bağımlılıklar ile mücadele konusunda uygulanabilir politikalar geliştirilmeli ve bireylerin bu konudaki farkındalıklarının arttırılması sağlanarak bağımlılıklarından kurtulmaları teşvik edilmelidir. Aksi taktirde sayısal veriler, bu ve benzeri önlemlerin alınmaması durumunda obezite ve beraberinde ortaya çıkan hastalıkların bu yüzyılda önemli bir sağlık sorunu olacağını göstermektedir. 


\title{
EXTENDED ABSTRACT
}

\section{Socio-Economic Determinants of Obesity: Analysis of OECD Countries}

\author{
Abdüsselam Sağın - Fatih Karasaç \\ Kırklareli University
}

Obesity is a growing problem for both developed and developing economies. Obesity, which is fat accumulation at a risk to health, is also defined as body mass index greater than 30 . The World Health Organization (WHO) research on obesity shows that this problem is becoming an increasingly common global epidemic (WHO, 2018). This study aims to investigate how certain socio-economic factors, along with the main determinants of obesity, have created such a widespread threat which adversely affects the living standards of individuals.

In this study, the dynamics of obesity are discussed for 29 OECD and partner countries by using panel data analysis. The ratio of obese population in this countries was used as dependent variable. The other variables are determined as health expenditures per capita, unemployment rates, urbanization rate, alcohol consumption per capita, the ratio of smokers to the total population and the daily calorie intake per person.

The obesity variable shows the proportion of adults above 18 years of age with a body mass index above 30 in the total population. The health expenditures variable is used as the ratio of total health expenditures to GDP. Unemployment rate refers to the non-working population in the labor force in these countries. Urbanization rate refers to the ratio of people living in urban Alcohol consumption variable is refers the amount of alcohol consumed per person(liter); smoking is considered as the proportion of smokers in the total population. Finally, the daily calorie intake variable ise defined that the calory consumed per person per day.

Obesity and daily calorie intake variables were used from World Health Organization database, health expenditures and alcohol consumption were obtained from OECD statistics, and unemployment and urbanization data were obtained from World Bank data. 
It is considered that health problems are not the only reason for obesity, but socio-cultural background and environmental factors have crucial roles in this process. For this reason, the main determinants of this problem and the effects of socio-economic factors on obesity are examined in this study in the light of the data from health and medical field literature clarifying the problem of obesity. For this purpose, the effects of calorie intake, using alcohol, smoking, health expenditures, urbanization and the increasing unemployment rate caused by urbanization have been analyzed.

According to the findings of the study, the increase in daily calorie intake of individuals leads to high obesity rates. The average amount of calories that an adult needs to take daily is around 2000 calories. Taking calories above this will naturally be the cause of weight gain and obesity.

Considering that changing working and living standards increases the individuals' habit of consuming fast food, junk food and prepared foods, it will be inevitable that obesity will be a rising trend all around the world.

According to one another result obtained from the study, increasing urbanization is a significant factor triggering obesity. When taken into consideration that people living in rural areas have to do works which require more physical activities which causes them to burn more calories, it is inferred that urbanization decreases the individuals' physical activeness during the day.

With urbanization, working conditions have changed; hence, the new job opportunities in urban areas like deskbound works do not require physical activeness. As a result, they consume less energy and burn off less calories. Changing working conditions ultimately leads to an increase in the body mass index of individuals, thus causes obesity.

Another economic impact of increasing urbanization is high unemployment rates. With the changing social and economic structure, urban life is getting more attraction and migration from village to city is becoming more common which naturally increases the unemployment rates in the cities.

All results have significant implications in terms of indicating that obesity is one of the major health problems experienced in the 21st century. The steady increase in the obese population and the prevalence of childhood obesity indicate that this issue will be a serious health problem for many countries in the upcoming years. Prevention of obesity and obesity-related health problems is of great importance for individuals and governments. For this purpose, the access to healthy, nutritious and organic foods should be 
facilitated and public awareness of obesity should be provided. In addition, due to the health problems caused by the rapid and increasing urbanization should be managed with the incentives to increase the living standards in rural areas.

Finally, policies that can be used for overcoming food addictions should be developed and individuals should be encouraged to get over their addictions by raising their awareness. Otherwise, numerical data indicate that obesity and associated diseases will be threatening health problems in this century if such measures are not taken.

\section{Kaynakça / References}

Agrawal, P., ve Agrawal, S. (2015). Health care expenditure associated with overweight/obesity: a study among urban married women in Delhi, India. International journal of community medicine and public health, 2(3), 308-317.

Baltagi. B.H., (2005). Econometrics analysis of panel data, 3. Bask1, Chichester: John Wiley ve Sons.

Baltagi B.H. (2011). Econometrics . Fifth edition. Berlin: Springer Verlag,

Bansal, S., ve Zilberman, D. (2016, November). Does health care expenditure counter adverse effects of obesity on health: Evidence from global data. In 2017 Allied Social Science Association (ASSA) Annual Meeting, January 6-8, 2017, Chicago, Illinois (No. 250115). Agricultural and Applied Economics Association.

Chou, S. Y., Grossman, M., ve Saffer, H. (2004). An economic analysis of adult obesity: results from the Behavioral Risk Factor Surveillance System. Journal of health economics, 23(3), 565-587.

Driscoll, J. ve Kraay, A. C. 1998. Consistent covariance matrix estimation with spatially dependent data. Review of Economics and Statistics, 80, 549-560.

Finkelstein, E. A., ve Strombotne, K. L. (2010). The economics of obesity. The American journal of clinical nutrition, 91(5), 1520S-1524S.

Greene, W. H. (2003), Econometric Analysis (5. Edition), New Jersey: Prentice Hall, Georgiou, M. N. (February 28, 2013). Obesity and income distribution: A panel data analysis for Western World. Available at SSRN: https://ssrn.com/abstract=2226391 or http://dx.doi.org/10.2139/ssrn.2226391

Halicioglu, F. (2013). Dynamics of obesity in Finland. Journal of Economic Studies, 40(5), 644-657. 
Hayes, A., Chevalier, A., D'Souza, M., Baur, L., Wen, L. M., ve Simpson, J. (2016). Early childhood obesity: Association with healthcare expenditure in Australia. Obesity, 24(8), 1752-1758.

Hsiao, C., (2002). Analysis of panel data (2. Edition), Cambridge University Press, New York.

Huffman, S. K., ve Rizov, M. (2007). Determinants of obesity in transition economies: the case of Russia. Economics ve Human Biology, 5(3), 379391.

Komlos, J., ve Baur, M. (2004). From the tallest to (one of) the fattest: the enigmatic fate of the American population in the 20th century. Economics ve Human Biology, 2(1), 57-74.

Laitinen, J., Ek, E., ve Sovio, U. (2002). Stress-related eating and drinking behavior and body mass index and predictors of this behavior. Preventive medicine, 34(1), 29-39

Laitinen, J., Power, C., Ek, E., Sovio, U., ve Järvelin, M. R. (2002). Unemployment and obesity among young adults in a northern Finland 1966 birth cohort. International journal of obesity, 26(10), 1329.

Lakdawalla, D., ve Philipson, T. (2002). The growth of obesity and technological change: a theoretical and empirical examination(No. w8946). National Bureau of Economic Research.

Loureiro, M. L., ve Nayga, R. M. (2004, August). Analyzing cross-country differences in obesity rates: some policy implications. In American Agricultural Economists Meetings, Denver, CO, August(pp. 1-4).

Maheshwari, N., Robinson, J. G., Kohatsu, N., ve Zimmerman, B. (2005). Obesity Prevalence Increasing 3 Times Faster in High than Low Income Groups: National Health and Nutrition Examination Surveys 1971 to 2002: 26. Circulation, 111(14), e190.

Maillard, G., Charles, M. A., Thibult, N., Forhan, A., Sermet, C., Basdevant, A., ve Eschwege, E. (1999). Trends in the prevalence of obesity in the French adult population between 1980 and 1991. International journal of obesity, 23(4), 389-394.

Mohan, R., ve Mirmirani, S. (2007). An assessment of OECD health care system using panel data analysis. Southwest Business ve Economics Journal, 16, 1-20.

Nestle, M., ve Jacobson, M. F. (2000). Halting the obesity epidemic: a public health policy approach. Public health reports, 115(1), 12-24. 
Özçiçek, F., Bilen, H., Yıldız, G., Özçiçek, A., Ünüvar, N., ve Yılmaz, A. (2007). Sigaranın bırakılmasından sonra görülen kilo alımı ile serum leptin düzeyleri arasındaki ilişki. CÜ Tip Fakültesi Dergisi, 29(4), 141-48.

Paola, M., Marotta, G., Nazzaro, C., ve Simonetti, B. (2012). A statistical approach to evaluate the effects of obesity on healthcare expenditure. Electronic Journal of Applied Statistical Analysis, 5(3), 418-424.

Pesaran, M. (2004). General diagnostic tests for cross section dependence in panels (No. 1240). Institute for the Study of Labor (IZA).

Philipson, T. J., ve Posner, R. A. (1999). The long-run growth in obesity as a function of technological change (No. w7423). National bureau of economic research.

Philipson, T. (2001). The world-wide growth in obesity: an economic research agenda. Health economics, 10(1), 1-7.

Popkin, B. M. (1999). Urbanization, lifestyle changes and the nutrition transition. World development, 27(11), 1905-1916.

Rashad, I. (2006). Structural estimation of caloric intake, exercise, smoking, and obesity. The Quarterly Review of Economics and Finance, 46(2), 268-283.

Rosin, O. (2008). The economic causes of obesity: a survey. Journal of Economic Surveys, 22(4), 617-647.

Sturm, R., An, R., Maroba, J., ve Patel, D. (2013). The effects of obesity, smoking, and excessive alcohol intake on healthcare expenditure in a comprehensive medical scheme. South African Medical Journal, 103(11), 840-844.

Wardle, J., Waller, J., ve Jarvis, M. J. (2002). Sex differences in the association of socioeconomic status with obesity. American journal of public health, 92(8), 1299-1304.

World Health Organization. (2018). Global status report on alcohol and health 2018. World Health Organization.

\section{Kaynakça Bilgisi / Citation Information}

Sağın, A. ve Karasaç, F. (2020). Obezitenin sosyo-ekonomik belirleyicileri: OECD ülkeleri analizi. OPUS-Uluslararası Toplum Araştırmaları Dergisi, 15(21), 183-200. DOI: 10.26466/opus.613617 